\title{
Joe Greene Selected for 1999 David Turnbull Lectureship for Contributions to the Science of Thin Films
}

\begin{abstract}
As an educator who has been named "outstanding teacher" every semester he has taught at the University of Illinois and as a pioneering contributor to research in the areas of the growth mechanisms of thin films and multilayers, the development of hard coatings, the use of energetic ions in controlling crystal growth, and in the development and understanding of metastable semiconductor thin film alloys, Joe Greene has been selected to deliver the 1999 Materials Research Society's David Turnbull Lecture. He is cited for "contributions to the use of nonthermal methods in the growth of thin films and the engineering of their phase, composition, and microstructure; and for excellence in teaching and writing."
\end{abstract}

The David Turnbull Lectureship recognizes the career of a scientist who has made outstanding contributions to understanding materials phenomena and properties through research, writing, and lecturing, as exemplified by David Turnbull.

Through his work in the areas of thin film science and surface engineering, Greene has focused on the controlled manipulation of the microchemistry, the microstructure, and thereby the physical properties of a wide array of systems. With his work on the use of energetic ion and photon beams, he has created new materials and improved existing ones in the development of wear coatings. Greene has also developed a new class of metastable semiconducting (III-V $)_{1-x}\left(\mathrm{IV}_{2}\right)_{x}$ alloys that include $(\mathrm{GaAs})_{1-x}\left(\mathrm{Si}_{2}\right)_{x}$, referred to as Greene alloys.

In his seminal contributions to the development of Si atomic-layer epitaxy (ALE), Greene used techniques such as scanning tunneling microscopy (STM), synchrotron radiation photoemission, and electron energy loss spectroscopy (EELS) to probe atomic-scale changes in the local chemistry and structure as layers were formed atom-by-atom. He developed the basic surface science of Si ALE, followed by applications to real-world growth and device manufacturing which has since been implemented by electronic companies in the United States and Japan. His work on low-energy, accelerated-ion doping during molecular beam epitaxy of $\mathrm{Si}$ and $\mathrm{Si}_{1-x} \mathrm{Ge}_{x}$ film growth has led to the modification of film properties for electronic and optical devices.

In collaborative work with colleagues at Linköping University in Sweden, Greene

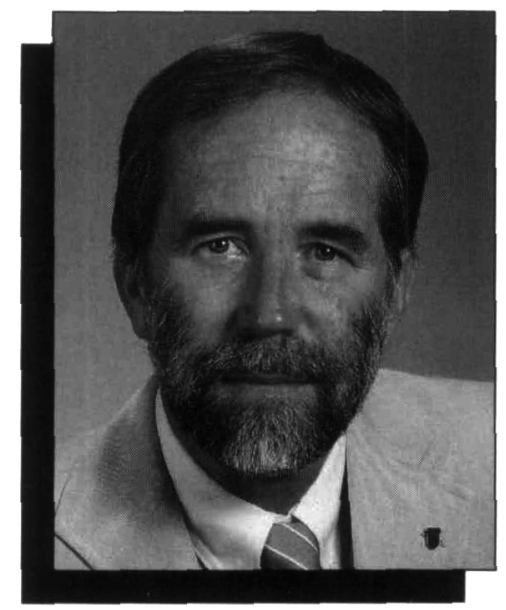

Joe Greene

revolutionized the hard-coating industry through studies on $\mathrm{Ti}_{1-x} \mathrm{Al}_{x} \mathrm{~N}$ and related alloys. Greene and his research group did pioneering work on surface morphological evolution of hard coatings and were the first to use in situ atomic-resolution hightemperature STM to follow the dynamics of island formation and decay during the growth of TiN by ultrahigh vacuum reactive magnetron sputter deposition.

Greene has been awarded many honors during his research career, including the Tage Erlander Professorship of Physics at Linköping University awarded every three years by the Swedish Natural Science Research Council, and the Doctor of Science Degree, honoris causa, from Linköping; the John Thorton Award from the American Vacuum Society (AVS); the Technical Excellence Award from Semiconductor Research Corporation (SRC); the R.F. Bunshah Award (in 1994 and 1998); and the U.S. Department of Energy Award for Sustained Outstanding Research in Metallurgy and Ceramics. $\mathrm{He}$ has been named Fellow of AVS and the American Physical Society (APS).

The University of Mlinois at Urbana has named Greene as the first W.B. Willett College of Engineering Professor in recognition of his research and his outstanding teaching reputation. Two of his recently developed courses, "Materials Science of Thin Films' and Electronic Properties of Solids," are among the most popular graduate courses in the Materials Science Department. Greene is known to encourage his graduate and undergraduate students to participate at every level of his research and to involve them in collabora- tions with scientists worldwide. His students have received nationally competitive fellowships and graduate student awards and have made a significant impact on various areas of materials research.

Greene has received numerous recognitions for his teaching, including the SRC Aristotle Award, the David Adler Lectureship Award in Materials Physics from APS, and the AVS Distinguished Lectureship. Greene has delivered 22 plenary or opening addresses at international conferences and more than 270 invited lectures at scientific meetings, universities, and research laboratories. By invitation, he has addressed the Danish, Dutch, Hungarian, and Swedish Academies of Science during centennial-year anniversary celebrations. He has authored 23 book chapters, co-edited four books, and published more than 310 articles.

In the science community, Greene has held leadership positions in AVS, APS, the International Union of Vacuum Science and Techniques, and the American Institute of Physics. He has served on policy and evaluation panels for DOE, the National Science Foundation, and the Department of Defense. Greene is currently Editor-in-Chief of Thin Solid Films; has served as editor of CRC Critical Reviews in Solid State and Materials Science; and has served on the editorial boards of several journals, including the Brazilian Journal of Vacuum Science and Technology, Physics Today, and the Journal of Vacuum Science and Technology.

Greene received his MS (1968) and $\mathrm{PhD}$ (1971) degrees in materials science from the University of Southern California. He joined the University of Illinois in 1971 and is currently head of the Electronic Materials Division in the Materials Science Department and director of the Frederick Seitz Materials Research Laboratory and the Center of Microanalysis of Materials.

The award will be presented to Greene at the 1999 MRS Fall Meeting during the Awards Ceremony on Wednesday, December 1, at 6:00 p.m. in Salon E of the Boston Marriott Hotel. He will present his lecture, "Atomic-Level Control During Film Growth Under Highly Kinetically Constrained Conditions: H-Mediation and Ultrahigh Doping in $\mathrm{Si}_{1-x} \mathrm{Ge}_{x}$ Gas-Source $\mathrm{MBE}^{\prime \prime}$ as part of the joint session of Symposia I and $N$ on Thursday, December 2, 11:15 a.m. in the Wellesley Room in the Boston Marriott Hotel. 